\title{
MORALES, Angélica Góis. A formação do profissional educador ambiental: reflexões, possibilidades e constatações. 2. ed. Ponta Grossa: UEPG, 2012. 223 p.
}

\author{
Márcia Silvana Rodrigues Voichicoski* \\ Camila Santana Caldeira**
}

Angélica Góis Morales, em seu livro "A formação do profissional educador ambiental: reflexões, possibilidades e constatações", cumpre o papel de colaborar com as discussões sobre a formação dos profissionais educadores ambientais e sobre como as instituições de Ensino Superior incorporaram a vertente socioambiental em seus cursos. A obra é fruto da tese de Doutorado realizada na Universidade Federal do Paraná (UFPR), defendida em 2007, publicada na forma de livro em 2009, revisada e ampliada em 2012.

A autora é docente da Universidade Estadual Paulista Júlio de Mesquita Filho (UNESP), possui licenciatura em Ciências Biológicas, Mestrado em Educação Ambiental, Doutorado em Meio Ambiente e Desenvolvimento e vasto conhecimento na área de educação ambiental.

Seu livro encontra-se organizado em cinco capítulos, os quais encaminham o leitor pela história e institucionalização da educação ambiental, o papel das universidades, até se ater ao processo de formação do profissional educador ambiental, apresentado no estudo de caso sobre o curso de Especialização em Educação, Meio Ambiente e Desenvolvimento da UFPR.

No capítulo 1, a obra aponta que a educação ambiental se forma e reforma dentro do contexto histórico e social e, nesse sentido, Morales descreve as diferentes ênfases sobre a relação ser humano e meio ambiente. Na sequência, a autora apresenta o processo de institucionalização da educação ambiental mediante os eventos internacionais e nacionais que delinearam as visões de meio ambiente e a configuração da legislação brasileira sobre o tema.

Morales identifica, com o apoio teórico de Castells, algumas tendências do movimento ambientalista e concepções de educação ambiental a partir de Sato e Sauvé, demonstrando o quanto esta vertente educacional é heterogênea e pluralista. Chama a atenção para o fato de que o discurso sobre a educação ambiental carrega, por vezes, uma visão naturalista e antropocêntrica, na qual os principais

\footnotetext{
* Mestre em Educação pelo PPGE da Universidade Estadual de Ponta Grossa. E-mail: < mar_sil_rod@yahoo.com.br>

** Mestre em Educação pelo PPGE da Universidade Estadual de Ponta Grossa. Email: <camila.caldeira@gmail.com>
} 
problemas abordados - poluição e redução de recursos naturais - são resultantes do predomínio das correntes empírico-analíticas.

A autora também se fundamenta em autores como Brügger, Carvalho, Grün, Leff e Morin para descrever as concepções de ambiente e educação ambiental. A partir disso, encaminha-se para uma visão crítica da educação ambiental, indicando a corrente crítico-reflexiva e emancipatória de Paulo Freire. Essa linha freireana está pautada na, pela e para a ação, o que implica a ação e reflexão dos seres humanos sobre o mundo para transformá-lo.

No capítulo 2, fundamentada em Leff, Morales aponta os referenciais epistemológicos para a formação do profissional educador ambiental, que, sob seu ponto de vista, são os princípios da sustentabilidade, interdisciplinaridade e complexidade.

O primeiro princípio citado, o da sustentabilidade, possui relação com a capacidade de suporte da natureza baseada nos pilares do desenvolvimento sustentável. Morales evidencia a variedade de sentidos relacionados com os termos sustentabilidade, ecodesenvolvimento ${ }^{1}$ e a expressão desenvolvimento sustentável, consolidada a partir da década de 80.

O segundo princípio está relacionado com a busca pelo suporte interdisciplinar essencial ao processo formativo da educação ambiental, a fim de superar os territórios disciplinares rumo à construção de um caminho epistemológico voltado para a promoção de um diálogo que aproxime os saberes específicos. Já o princípio da complexidade se articula com os anteriores e se apresenta como um desafio na busca por novas abordagens do conhecimento, em razão da fragilidade e limitações presentes no pensamento disciplinar.

Na segunda edição do livro, Morales incluiu um subitem "Multiculturalismo, complexidade e educação ambiental", citando mais um ponto importante no processo formativo do profissional educador ambiental, que está relacionado ao pensar a relação entre igualdade e diferença.

Diante destes princípios abordados pela autora, nota-se que o desafio na formação dos profissionais educadores ambientais seria a articulação do conhecimento de forma interdisciplinar e complexa, pautada nas ideias de sustentabilidade, que muitas vezes se remetem ao mero desenvolvimento econômico da lógica capitalista. Ainda atrelado a esses elementos, surge outro desafio, possibilitar a esses profissionais subsídios que lhes permitam lidar com as contradições e disputas existentes no campo ambiental, uma vez que este é carregado de intencionalidades.

${ }^{1}$ Termo introduzido por Maurice Strong divulgado por Ignacy Sachs. 
No capítulo 3, a autora sinaliza a necessidade de uma formação crítica na universidade por meio de um ambiente de discussão e valorização dos diversos saberes. Para tanto, destaca que a universidade precisa estar aberta aos desafios da abordagem socioambiental em busca da emancipação social.

Dessa forma, a autora direciona o assunto do livro para o seu ponto principal: a discussão sobre a formação do profissional educador ambiental. Assim, Morales descreve como ocorreu o crescimento dos cursos de pós-graduação a partir de meados da década de 80 e o papel dos seminários nacionais sobre a universidade e o meio ambiente. Esses fatos levaram a um aprofundamento, mesmo que limitado, da temática ambiental nas instituições de Ensino Superior.

Conforme a autora, "a pós-graduação parece ser o espaço mais conveniente de um programa ambiental específico, por ter maior abertura na incorporação interdisciplinar da dimensão ambiental" (MORALES, 2012, p. 107), uma vez que a educação ambiental abrange todas as áreas do conhecimento, não sendo, portanto, uma disciplina ou uma questão isolada. Nesse encaminhamento, Morales reafirma a constatação feita por Carvalho (2001) de que a porta de entrada da educação ambiental na universidade se dá por meio da pós-graduação.

No quarto capítulo, Morales analisa a trajetória que alguns cursos percorreram para atingir a formação ambiental, focando seu trabalho no estudo de caso do Curso de Especialização em Educação, Meio Ambiente e Desenvolvimento da Universidade Federal do Paraná (UFPR).

Esse curso emergiu dentro do contexto do Programa Interdisciplinar do Doutorado em Meio Ambiente e Desenvolvimento da UFPR e foi contemplado por professores provenientes de diversos departamentos, havendo uma integração de distintas áreas do conhecimento (Biologia, Geografia, Agronomia, Pedagogia, Filosofia, Sociologia e Comunicação). Devido a essa ligação, a especialização caracteriza-se como um desdobramento do curso de doutorado e, em razão disso, apresenta um núcleo epistemológico das ciências sociais e naturais que se confluem, articulando a estas a educação ambiental e as disciplinas pedagógicas.

Para realizar sua pesquisa, a autora entrou em contato com 50 alunos egressos do curso de especialização, no período entre 2003 e 2005 (totalizando 3 turmas). Obteve o retorno de 32 deles, sendo que 22 atuavam na área da educação ambiental. Dentre estes, foram selecionados, de acordo com o tempo de atuação na área, 12 profissionais educadores ambientais para participarem da pesquisa por meio de entrevistas semiestruturadas. Também foram entrevistados os nove professores do curso de especialização para uma análise mais ampla.

A partir dos resultados desse trabalho, Morales utiliza a terminologia "profissional educador ambiental" para englobar os profissionais que passaram por um curso de especialização em educação ambiental provenientes de diversas 
áreas do conhecimento com o intuito de evidenciar as diferentes formações iniciais, como no caso do curso estudado: Administração, Engenharia Florestal, Engenharia Agronômica, Medicina Veterinária, Turismo, Geografia, Ciências Sociais, Letras, Pedagogia, Ciências Econômicas, Arquitetura e Urbanismo e Educação Artística.

No capítulo final, a autora apresenta os resultados, mostrando o perfil heterogêneo dos alunos e professores, os pontos positivos e as fragilidades do curso e, principalmente, os desafios e caminhos que a questão ambiental vem trilhando na educação, em especial na universidade e na especialização.

Para a organização dos dados, Morales utilizou a Análise de Conteúdo de Bardin por meio da qual emergiram duas dimensões: "inter-relacional" e "pedagógica".

A primeira dimensão "inter-relacional" foi composta pelas categorias: "Trajetória ambiental: motivações e experiências iniciais"; "Razões para buscar o curso de especialização"; e "A formação da identidade profissional do educador ambiental: desdobramentos do curso".

Dentre as motivações dos sujeitos para adentrar o campo ambiental, destacam-se a influência familiar, a trajetória profissional e/ou pessoal, fatores políticos ou a própria universidade. Outro ponto importante detectado foi o de que a maioria dos entrevistados teve contato profissional com a Educação Ambiental entre 1999 e 2003 que segundo Carvalho (2001) se caracteriza como a "nova geração" de educadores ambientais, quando comparados com profissionais que atuam desde a década de 60 e 70.

Entre as razões que levaram os alunos egressos a optar pelo curso de especialização estão a possibilidade na (re)inserção na vida acadêmica, a necessidade de aprimoramento profissional teórico-prático e a ampliação de conhecimentos vinculados aos projetos ambientais já desenvolvidos que, frequentemente, carregavam "[...] um fazer pragmático descolado de um conhecimento teórico aprofundado" (MORALES, 2012, p. 156).

Em relação à formação da identidade profissional do educador ambiental, a autora identificou, por meio da fala de um sujeito de sua pesquisa, que a área ambiental na escola e na universidade não é uma dimensão abordada. Diante disso, Morales reforça a urgência e a necessidade de se inserir a educação ambiental na formação de profissionais de modo a se construir uma nova racionalidade socioambiental.

A partir da fala dos entrevistados, salienta que apesar das possibilidades resultantes do curso investigado, a educação ambiental ainda não é prioridade para os órgãos governamentais e privados. Neste ponto, Morales evidencia que a 
"[...] identidade profissional tende a ser cada vez mais reconhecida à medida que os resultados das ações desses profissionais sejam reconhecidos pela sociedade brasileira" (MORALES, 2012, p. 163).

$\mathrm{Na}$ dimensão "pedagógica", contemplam-se as categorias: "Percepções do curso de especialização: pontos fortes, pontos fracos e aspectos mais trabalhados", "Fundamentos teórico-metodológicos do profissional educador ambiental: a) concepção de Educação Ambiental, b) (re)construção do referencial teórico-metodológico na Educação Ambiental", "Percepções do curso de especialização e da prática docente" e "Percepções quanto à educação ambiental".

Essa dimensão apresenta dois momentos, sendo que o primeiro contempla a avaliação pedagógica do curso de especialização, as percepções em relação ao curso, os subsídios teórico-metodológicos do profissional educador ambiental sob a ótica dos alunos egressos e o segundo momento remete as percepções do curso de especialização, da prática pedagógica e a percepção quanto à educação ambiental na visão dos professores.

Na categoria "Percepções do curso de especialização: pontos fortes, pontos fracos e aspectos mais trabalhados", Morales destaca como potencialidades a fundamentação teórica consistente de educação ambiental, pautada numa perspectiva interdisciplinar, reflexiva e crítica; exigência e incentivo ao trabalho de pesquisa; corpo docente experiente e exigente; entre outros. Em relação às fragilidades do curso encontra-se a discussão insuficiente da educação ambiental não formal; a pouca aplicação prática; linguagem complexa por parte dos professores; entre outros. Dentre os aspectos mais trabalhados no curso estão: a sólida formação teórico-metodológica, perspectiva interdisciplinar e a formação crítica.

A categoria "Fundamentos teórico-metodológicos do profissional educador ambiental" reúne aspectos conceituais e teórico-metodológicos de educação ambiental. Nesse momento, para identificar a compreensão sobre educação ambiental, Morales indagou os egressos sobre a forma como concebiam essa prática e as possíveis mudanças conceituais que ocorreram após o curso. A autora concluiu que a mudança foi em relação à visão reducionista que se tinha dos problemas ambientais, alcançando-se uma visão mais crítica e complexa de meio ambiente. Nesse sentido, os aspectos teórico-metodológicos do curso possibilitaram a (re)construção de conceitos socioambientais, a (re)organização de pensamento e ação por parte dos egressos e, por conseguinte, permitiram que cada profissional lançasse um novo olhar ambiental em seu objeto de estudo que por sua vez pode ter possibilitado uma qualidade maior no trabalho desses profissionais que atuam com educação ambiental.

Mediante as falas dos sujeitos entrevistados e dos fundamentos teóricos da educação ambiental, emergiu, na pesquisa de Morales, a concepção relação 
entre sociedade-natureza. Dessa forma, a maioria dos sujeitos atrelou a educação ambiental sob a ótica da corrente crítico-reflexiva de Paulo Freire e também na teoria crítica que por sua vez estão ancoradas na vertente transformadora e progressista.

Ainda na dimensão pedagógica, tem-se o olhar dos professores frente ao curso de especialização, a prática docente e a percepção de educação ambiental. Todos os professores foram unânimes em afirmar que a perspectiva interdisciplinar perpassa o desenvolvimento do curso, o que sinaliza para a autora que as práticas docentes se aproximam dos princípios teórico-metodológicos. Segundo Morales, esses professores também podem ser considerados profissionais educadores ambientais, tendo em vista que trabalham com ensino e pesquisa em educação ambiental.

Os limites provenientes do curso estão relacionados à dificuldade em trabalhar a questão socioambiental de forma interdisciplinar devido aos prazos limitados da carga horária da especialização. Em razão disso, não é possível uma relação aprofundada diante da complexidade do tema.

Além das fragilidades teórico-metodológicas, são apontadas outras decorrentes do corpo discente e da estrutura do curso. Os problemas relacionados ao corpo discente se referem à ausência de aporte teórico ou conhecimentos preliminares necessários para os estudos socioambientais. Em relação à estrutura do curso, destaca-se a ausência de reuniões entre o corpo docente, a impossibilidade de visualizar o reflexo da disciplina na formação dos alunos e entre as demais disciplinas.

$\mathrm{Na}$ última categoria "percepção quanto à educação ambiental”, Morales detectou que as percepções ambientais convergiam com as vertentes construtivistas e crítico-reflexivas, o que sinaliza, conforme a autora, a construção de uma possível epistemologia da educação ambiental, pautada na racionalidade socioambiental sob a ótica da complexidade. Portanto, constata a autora que o curso de especialização estudado parece cumprir seu papel, uma vez que promove o diálogo de saberes mediante a perspectiva interdisciplinar, contemplando as questões sociais e ambientais.

É possível observar que conforme a temática ambiental ganha repercussão, aumenta a necessidade de reflexão sobre a formação dos profissionais educadores ambientais. No livro ora resenhado, a autora trata de maneira muito clara e objetiva o tema, o que possibilita que os alunos, profissionais e pesquisadores de diferentes níveis de formação possam realizar uma boa leitura. Sendo assim, o livro apresenta-se como um meio para a reflexão sobre a formação de todos os profissionais, sobretudo aqueles que se sentem sensibilizados pela questão ambiental e que de alguma forma almejam (re)construir e (re)pensar sua trajetória 
profissional, marcada, por vezes, pelo reducionismo e pela fragmentação do conhecimento.

Nesse momento precisamos lembrar que a universidade tem um compromisso social, pois forma cidadãos e, apesar de suas limitações, deve assumir sua responsabilidade no processo de produção e incorporação da dimensão ambiental nos sistemas de formação profissional, além de propiciar fundamentos teórico-práticos baseando-se na complexidade e interdisciplinaridade que a questão ambiental exige.

Mesmo considerando que a universidade ainda não está preparada para assumir desafios de mudanças estruturais e organizacionais, existe a necessidade de reformas de mentalidades (MORIN, 2003). Apesar das diversas fragilidades, é preciso reconhecer que os cursos de pós-graduação voltados para educação ambiental colaboram com a mediação das discussões socioambientais e dispõem de um grande potencial de se tornarem um espaço de mudanças e comprometimento com a formação socioambiental no Ensino Superior.

\section{Referências}

CARVALHO, I. C. M. A invenção ecológica: narrativas e trajetórias da educação ambiental no Brasil. Porto Alegre: UFRGS, 2001.

MORIN, E. A cabeça bem-feita: repensar a reforma, reformar o pensamento. 8. ed. Rio de Janeiro: Bertrand Brasil, 2003. 